\title{
Steel-Tinplate as a solar wall panel and its effectiveness
}

\author{
G. Ruskis ${ }^{*}$, A. Aboltins, J. Palabinskis \\ Institute of Agricultural Machinery, Latvia University of Agriculture, Cakstes blvd. 5, Jelgava, LV-3001, \\ Latvia \\ *Corresponding author. Tel: +371 29490286, Fax: +371 63020762, E-mail: guntisruskis@inbox.lv
}

\begin{abstract}
The aims of the research, was to investigate black colored steel-tinplate use for absorber and covered material of collector and compare the efficiency of three types of air heating collectors. This heated air we can exploited for drying of agricultural produce, room ventilation and room heating and etc.

$0.1 * 0.5 * 1.0$ meters long flat-plate collector (FPC) for experimental research was built. Air velocity at the experiments was $\mathrm{v}=0.9 \mathrm{~m} / \mathrm{s}$. We used the sun following collectors. The experimental data were measured and recorded in the electronic equipment (REG). The experiments were carried out in September 2010 at the same weather conditions.

Collectors of insulated and un-insulated surfaces with steel-tinplate absorber as covering material warmed ambient air up to 10-12 and 5-6 degrees corresponding (at irradiance $800 \mathrm{~W} / \mathrm{m}^{2}$ ). This difference indicates the great importance of insulating the collector body. It can explain with intensify heat exchange between absorber and ambient air which reduce efficiency of collector. There was good correlation with irradiance and air heating degree.

Our investigations showed that more effective FPC was collector with absorber tinplate at middle of collector body. At favorable weather conditions the heating degree of ambient air at the outlet reaches 6-8 degrees more that at the outlet of insulated collector covered by steel-tinplate.
\end{abstract}

Keywords: Solar Energy, Air Heating, Collector, Solar Wall, Absorber.

\section{Introduction}

Under Kyoto targets, the European Commission member states and stakeholders identified and developed a range of cost-effective measures to reduce emissions. The new package sets a range of ambitious targets to be met by 2020, including improvement of energy efficiency by $20 \%$, increasing the market share of renewable to $20 \%$. In a renewable energy-intensive scenario, global consumption of renewable resources reaches a level equivalent to $318 \mathrm{EJ}$ $\left(E=10^{18}\right.$ ) per annum of fossil fuels by 2050 , but it is less than $0.01 \%$ of solar energy reaching the earth's surface each year [1].

Solar energy is used to heat and cool buildings (both actively and passively), drying production, heat water for domestic and industry use, heat swimming pools, generate electricity, for chemistry applications and many more operations [1].

One of the solar energy uses is a solar wall. Solar wall system is simple, effective, inexpensive, ecological, building integrated into any solution [2-3]. This system, raising the temperature of indoor air for 5 - 25 degrees above the outside air temperature, allowing to save $20-70 \%$ of fuel energy while supplying the area with fresh air.

This system successfully used around the world since 1977, when the Canadian government subsidized the eco-system tests. Solar wall missions are located in North America, Europe and Asia - a total of more than 25 countries worldwide.

There is no ne ed for heat ventilation at the expense of the economy, because the system provides fresh air circulation, while the walls of the building do not overheat in the summer, because the system acts as a coolant. In many countries, is increasing interest in solar wall panels use. Solar wall panels use is discussed a lot in works of Italian climates [4]. 
Using solar collectors efficiency studies [5], the idea was to use steel-tinplate absorber as a solar panel on the wall. Steel-tinplate absorber can be used on the roof, thereby providing ventilation and heating in early spring and autumn, with the heat and fresh air, and drying the products with heated air in the summer.

Our aim was to find the collector's (the adsorbent is used as a coating material) efficiency of insulation using and warm-up stage of air.

\section{Methodology}

The aim of the research was to investigate black colored steel-tinplate use for absorber and covered material of collector and compare the efficiency of three types of air heating collectors: collectors with insulated and un-insulated surfaces with covered material - steeltinplate and classical collector with covered material - polystyrol plate and absorber black colored steel-tinplate in middle. View of flat-plate collector (FPC) when the absorber (black colored steel-tinplate) is put in the middle of the collector is shown in Fig.1. In the second case, absorber placed collector coverage place, it means at the top of collector.

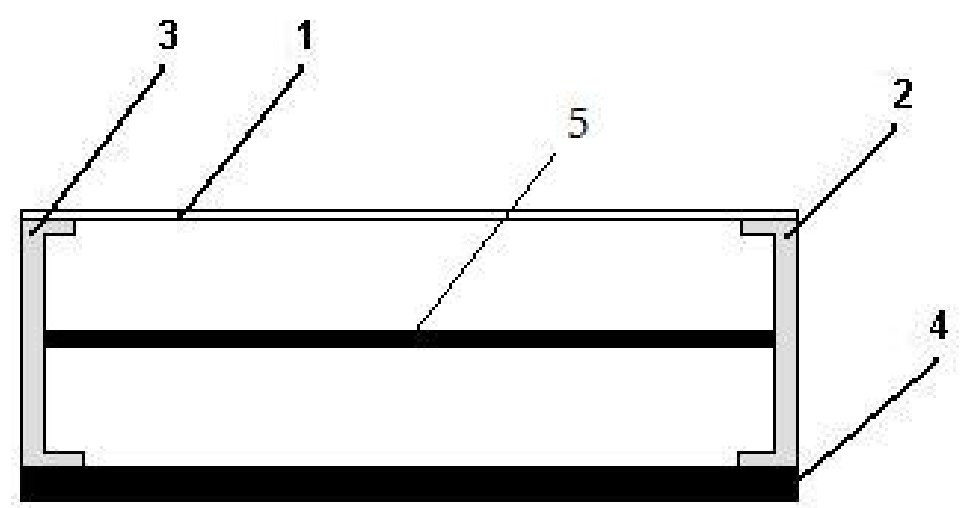

Fig. 1. Schema of solar collector frontal view: 1 - covered material; 2, 3 - side surface /plastic/; 4 floor of collector; 5 - absorber (steel-tinplate)

In the experiments, the collector covered material was a polystyrol plate. This material has gained immense popularity due to such properties as safety, mechanical crashworthiness, translucence and high UV radiation stability.

In the laboratory a $0.1 * 0.5 * 1.0$ meters long experimental solar collector was constructed for research into the properties of absorber materials. Air velocity at the experiments was $\mathrm{v}=0.9$ $\mathrm{m} / \mathrm{s}$. Our investigations devoted the sun following collectors, which guarantees perpendicular location of plane of absorber from flow of sun radiation.

Experimental data is recorded by means of an electronic metering and recording equipment of temperature, radiation and lighting (REG) [6]. It is equipped with 16 temperature transducers and metering sensors of solar radiation and lighting. Solar radiation measuring instrument was the pyranometer. The isolated collector was made by the collector surfaces faced with cellular plastic $2 \mathrm{~cm}$ plates.

We compare three equal sizes FPC: collectors of insulated and un-insulated surfaces with absorber steel-tinplate as a covering material and classic collector with the covering material polystyrene plate and absorber tinplate in the middle of collector. Experiments were made in 
September 2010 in different weather conditions at different atmospheric air temperatures. To assess different absorbers influence was made comparatively research at similar weather conditions. Inflow air temperature in collector is equal to the ambient air temperature. Ambient air temperature was changing from $13^{\circ} \mathrm{C}$ to $18^{\circ} \mathrm{C}$ in our experiments.

The data of sun radiation are depended from clouds, shadows and we aligned experimental data with method of least squares using Eq. (1). [7]

$$
\overline{y_{i}}=\frac{1}{35}\left[17 y_{i}+12\left(y_{i-1}+y_{i+1}\right)-3\left(y_{i-2}+y_{i+2}\right)\right]
$$

Where $\overline{y_{i}}$ - aligned data, $y_{i}$ - experimental data, $i$ - ordinal number.

\section{Results}

Using the experimental results and statistical processing data we received a relation between the length of the collector, sun radiation to absorber plate and air temperature exchange in the collector.

We research situation when absorber (steel-tinplate) puts at top of collector (Fig. 2). To compare insulated and un-insulated collectors with steel-tinplate as a covering material we can see that at the same weather conditions for insulated collector is warming up air to 3 degree up (at radiation $800 \mathrm{~W} / \mathrm{m}^{2}$ ) than collector with un-insulated surfaces (Fig. 3).

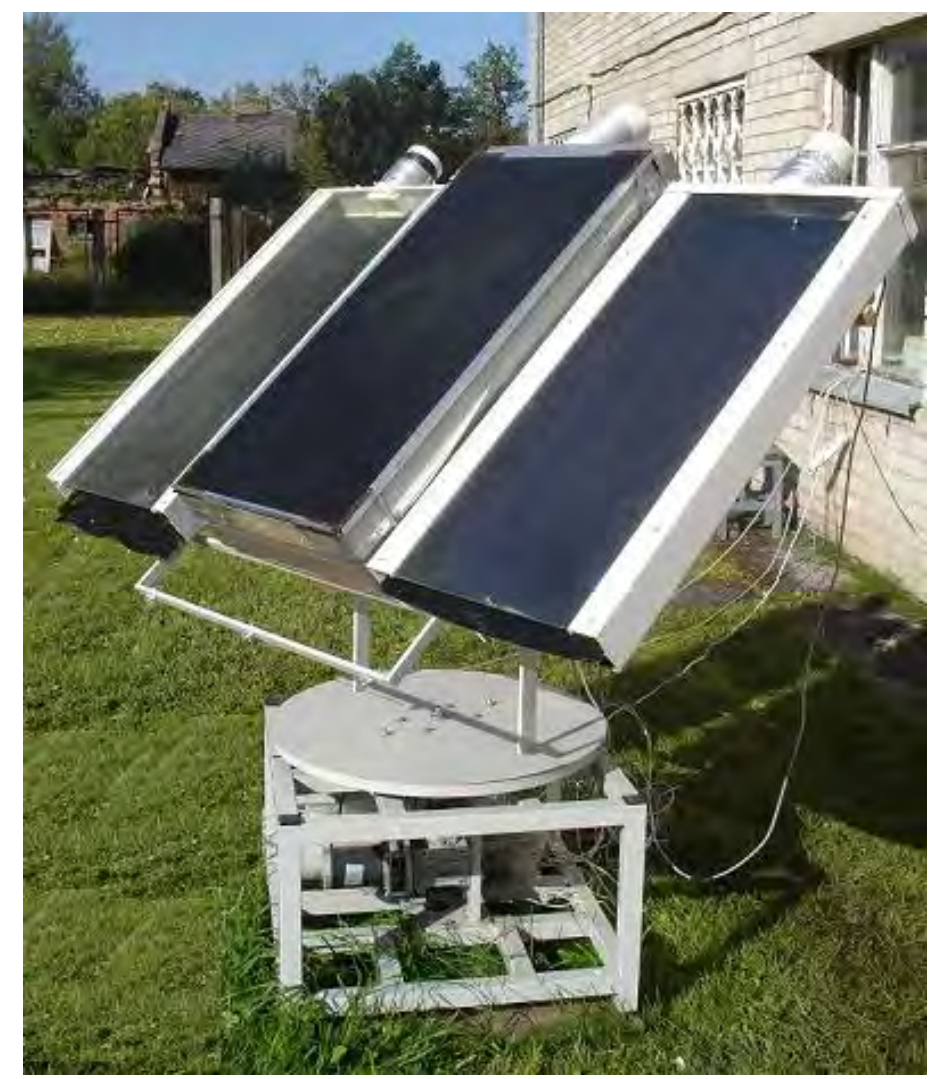

Fig. 2. Sun collector comparatively research in experiment. 
We can see that the solar radiation changes significantly affect the passing air temperature. This effect does not happen instantly, but with a delay of 3-5 minutes. It should be noted that the un-insulated collector efficiency is highly influenced by wind speed, which cools the surface of the collector body.

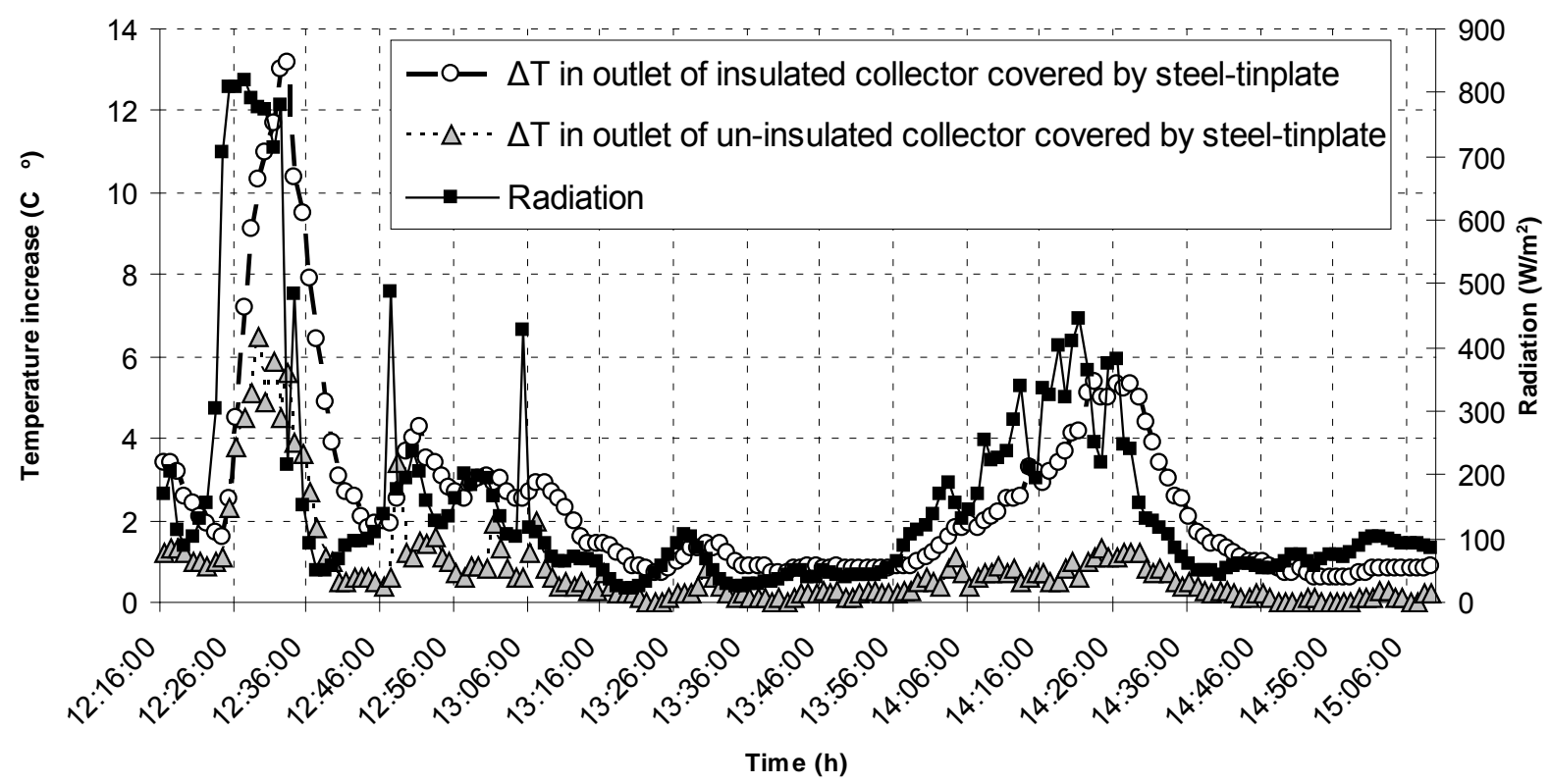

Fig. 3. Temperature difference in outlet of collector with steel-tinplate covering material for insulated and un-insulated surfaces comparing with sun radiation.

As you can see in Fig. 4, near little sun radiation are not visible constitutive air heating, but increasing sun radiation is growing air heating level and you can see that collector with absorber steel-tinplate at middle of collector body is more powerful than collector with steeltinplate absorber as covering material. Air heating level is not highly dependent on ambient temperature. Much more it is influenced by solar radiation and insulation. If the collector is covered with the steel tinplate then this collector efficiency is highly influenced by environmental conditions, especially wind and ambient air temperature. These conditions reduces absorber own temperature. In the classic collectors whose effects are much smaller (Fig. 4) 


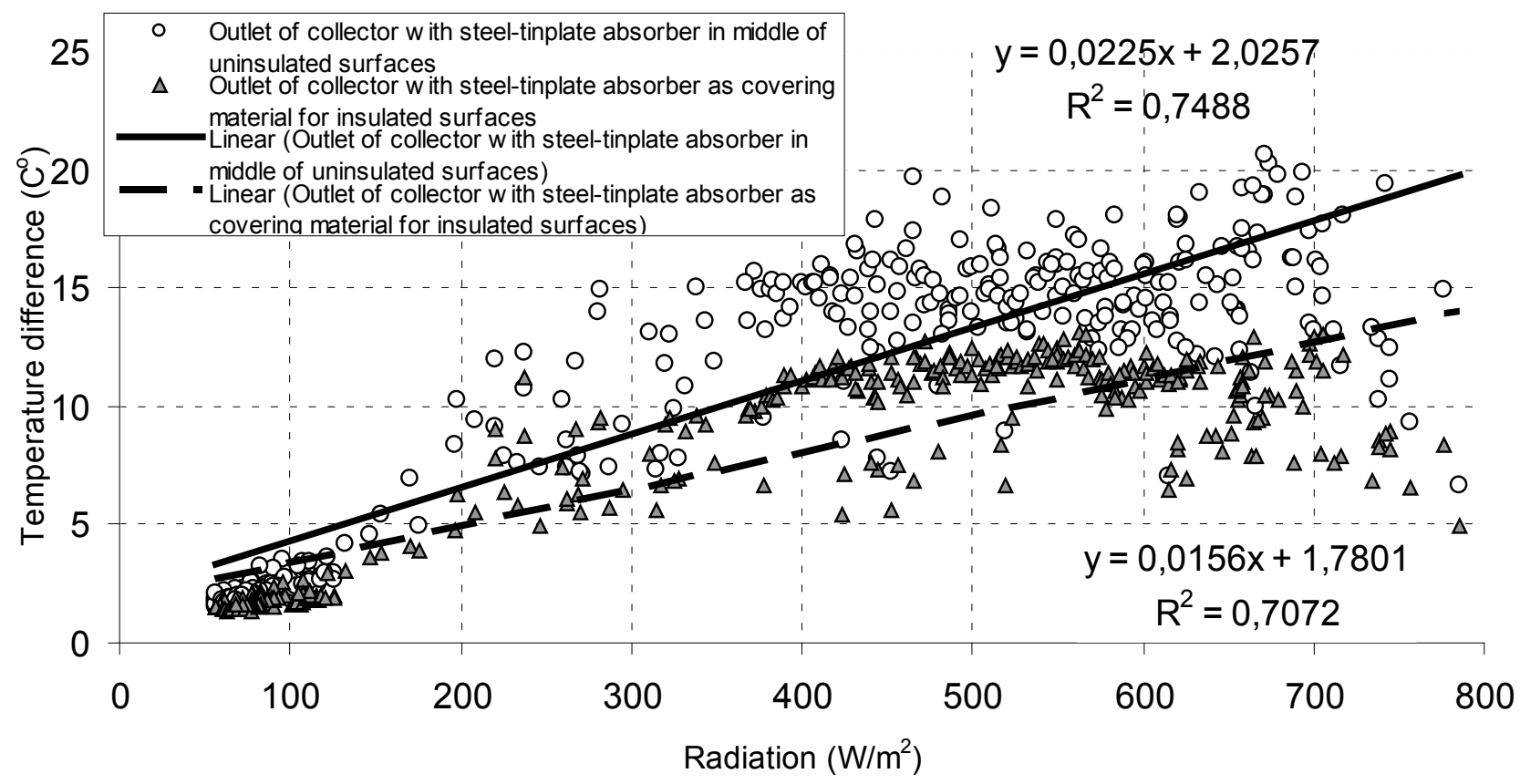

Fig. 4. Temperature difference in outlet of collector (with absorber tinplate at middle of collector body and with steel-tinplate absorber as covering material) comparing with sun radiation.

Near little sun radiation are not visible constitutive air heating, but increasing sun radiation is growing air heating level and you can see that collector with absorber steel-tinplate at middle of collector body is more powerful than collector with steel-tinplate absorber as covering material.

Using the experimental results and statistical processing data we received a relation between the air temperature exchange under the steel-thin plate absorber in the collector, length of the collector and sun radiation to absorber plate.

The temperature change $\Delta \mathrm{T}$ under tinplate can be expressed with the Eq. (2).

$$
\Delta T=1.3 \cdot 10^{-2} x \cdot R-4.8 \cdot 10^{-3} R-1.9 \cdot 10^{-6} R^{2}-0.3 x+0.68 x^{2},
$$

Where $\quad x-$ length of collector $(\mathrm{m}) ; R-$ sun radiation $\left(\mathrm{W} \cdot \mathrm{m}^{-2}\right)$.

Coefficient of determination is $\eta^{2}=0.771$. The graphical interpretation of Eq. (2) is shown in Fig.3.

In Fig. 5. you can see contour plot of air temperature (under absorbent) increase dependence on length of collector and sun radiation for un-insulated collector with absorber with steeltinplate as a covering material. 


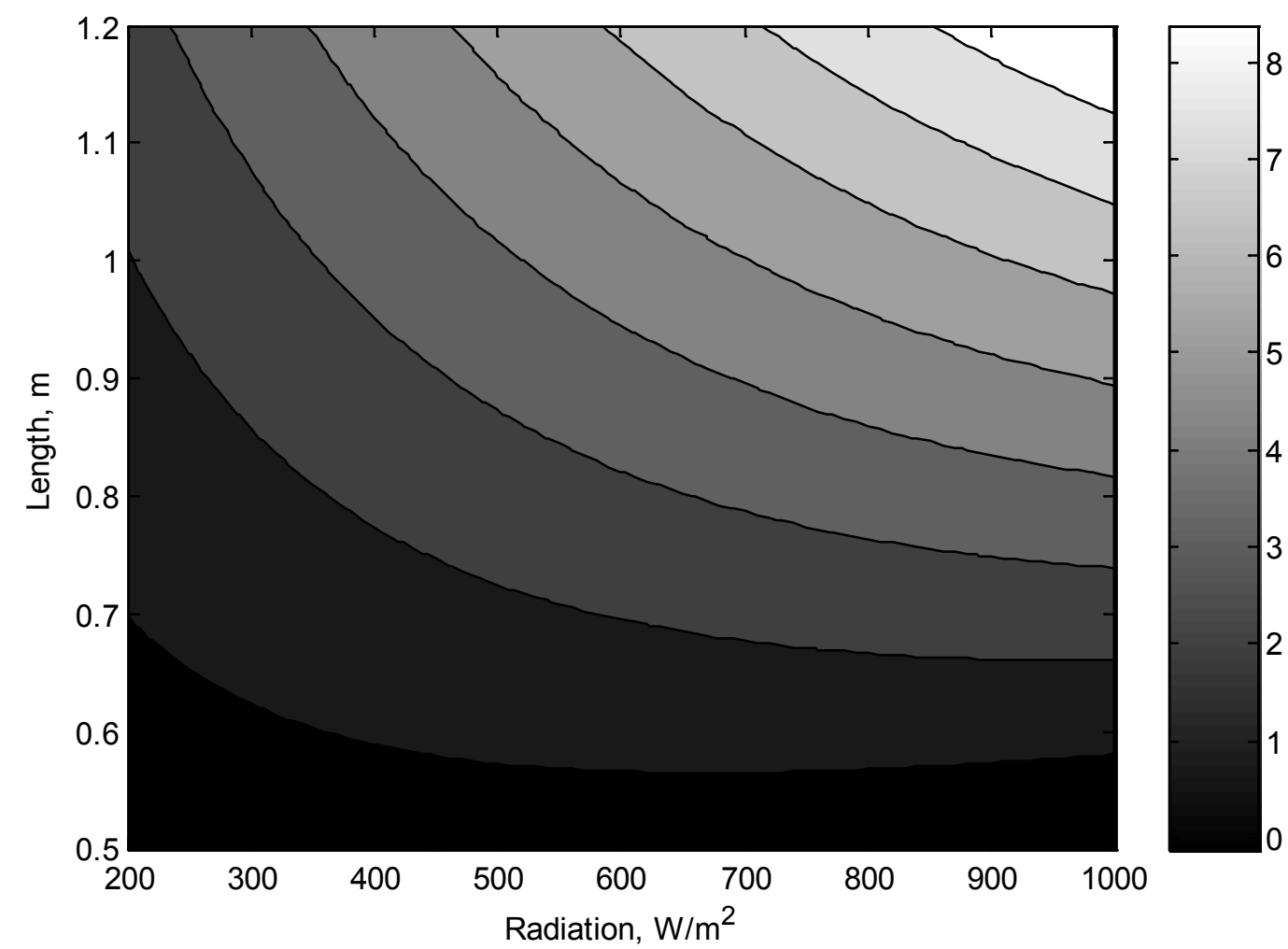

Fig. 5. Contour plot of air temperature (under tin plate) increase dependence on length of the collector and sun radiation.

\section{Conclusions}

1. Collectors of insulated and un-insulated surfaces with steel-tinplate absorber as covering material warmed ambient air up to 10-12 and 5-6 degrees corresponding (at irradiance $800 \mathrm{~W} / \mathrm{m}^{2}$ ). This difference indicates the great importance of insulating the collector body.

2. Use of isolation for collector construction dose not give inportant role if there is no wind to cool collector.

3. Using the experimental results and data statistical processing we received a relation between the air temperature exchange under the steel-thin plate absorber in the collector, length of the collector and sun radiation to absorber plate.

4. At favorable weather conditions the heating degree of ambient air at the outlet of collector with absorber tinplate at middle of collector body reaches 6-8 degrees more that at the outlet of insulated collector covered by steel-tinplate.

5. Our investigations showed that steel-tinplate absorber use as covered material of flatplate collector for ventilated air heating is possible in Latvia. 


\section{References}

[1].S. Kalogirou, Solar energy engineering: processes and systems, Academic Press Elsevier Inc., 2009.

[2].Solar Buildings: http://www.nrel.gov/docs/fy99osti/24499.pdf

[3].Solar wall: http://solarwall.com/en/products/solarwall-air-heating/uses-andapplications/agriculture.php

[4].F. Stazi, C. Di Perna, C. Filiaci, and A. Stazi, The Solar Wall in the Italian Climates, World Academy of Science, Engineering and Technology 37, 2008, pp. $31-39$.

[5].A. Aboltins, J. Palabinskis, A. Lauva, G. Rušķis, The steel-thin plate absorbers investigations in air solar collector, Proceedings of the 8th International Scientific Conference "Engineering for Rural Development", 2009, pp. $182-187$.

[6].REG 2004 Tehniskais apraksts un lietošanas pamācība (Technical description and using instruction), pp. 11. (in Latvian)

[7]. Веденяпин Г.В. Общая методика экспериментального исследования и обработки опытных данных (The general methology of experimental research and treatment of experimental data). Колос, М., 1967. (in Russian) 